\title{
Application of Blended Teaching in Hydraulic Pneumatic Transmission and Control Course Based on MOOC and FanYa Platform
}

\author{
Ruhe Zhao *, Yongsheng Li, Hui Huang, Dongqin Jiang \\ JinCheng College \\ Sichuan University \\ Chengdu, 611731, China
}

\begin{abstract}
The hydraulic pneumatic transmission and control course has the characteristics with difficult theory and complicated application in the teaching process. How to change the problems of traditional classroom teaching such as dull, monotonous, boring, relatively fixed teaching time and place, rigid learning methods, low learning efficiency, etc., the MOOC and SMOOC technology were studied. The FanYa platform was adopted to realize blended teaching. The teaching team was organized before class, and the curriculum syllabus was developed according to the talent training program, and the teaching program, teaching plan, teaching PPT, animation production and micro-lesson video shooting were completed. The FanYa platform was used to complete pre-class preview, preview effect tracking, classroom communication and discussion and homework. Through the pilot program in the last three years, the students can make full use of fragmented time and learn at any time and anywhere by adopting blended teaching method. Teachers can greatly improve teaching efficiency. This work summarized the material block diagram and execution process of blended teaching, and realized the four-in-one blended teaching in the traditional hydraulic pneumatic transmission and control course, including the combination of theory and practice, pre-class and after-class, online and offline, traditional classroom and network classroom.
\end{abstract}

Keywords-MOOC; Blended learning; Hydraulic pneumatic transmission and control; FanYa platform; Applied undergraduate

\section{INTRODUCTION}

At present, the traditional classroom teaching is a classroom with chalk, blackboard, PPT, multimedia as the core. Teachers are in an authoritative central position, and knowledge is imparted by teachers. Students have less time to practice, speak and use their brains. Classrooms are dull and students' learning efficiency is low. On the other hand, since the development of mobile Internet, mobile phones, IPAD, etc., are widely used to complete many functions such as listening to music, watching TV, playing games and even offices. Contemporary college students are basically staffed by a mobile phone. Can we use mobile Internet to complete learning? The answer is yes. Therefore, MOOC is popular, but there are many problems in the application of MOOC. Firstly, the form of MOOC is too simplistic. The teacher divides the 45 minute course of lectures into 3-4 classes, and fragments the knowledge points, hoping to use fragmented time to learn knowledge. However, fragmentation of knowledge will easily cause students to see trees and no forests, and long-term fragmentation learning will easily lose the correct and reasonable understanding of disciplines. Secondly, MOOC lacks the inspiration and guidance of traditional classroom due to lacks the teachers' guidance and supervision [1-3].

Whether we can find a teaching method that can't only cultivate students' active learning and give full play to students' enthusiasm and initiative in learning, but also enable teachers to change from teaching position to "coach" position, and actively track the progress and effect of learning in the teaching process. Students have relevant questions in the process of learning. Teachers can immediately solve and answer the questions in the process of learning, and students can also answer the relevant questions. It is easy to form a good learning atmosphere. Whether students can report the relevant learning progress regularly can provide an opportunity for direct communication with teachers. It can make full use of the current network technology, cloud platform and multimedia technology, while enjoying the advantages of traditional teaching, overcoming the traditional teaching mode of classroom dull and the shortcomings of students' passive learning [2-4].

The hydraulic pneumatic transmission and control course is the core professional basic course of every major in mechanical engineering. It is widely used in aerospace, engineering machinery, machine tool control, etc. However, this course has the characteristics of theoretical difficulty, abstraction, content, students generally reflect learning boring, and the principle is not easy to grasp. On the other hand, fluid transmission theory is a classical part of theory, which is widely used in practice. Students majoring in intelligent manufacturing must study the basic theory carefully. Whereas, students' interest in learning is not high. Based on superstar FanYa platform and combined with MOOC and SMOOC, the traditional classroom was reformed by the way of pre-class, after-class, online and offline blended teaching. Based on the detailed analysis of disciplines, this work carefully designed the syllabus, designed the teaching according to the three modules of pre-class, in-class and after-class, and recorded the related micro-lessons. After three years of implementation, some results have been achieved. 


\section{MOOC AND SMOOC}

MOOC (Massive Open Online Course) is a concept put forward by Canadian Dave Cormier and others to achieve large-scale online courses. Stanford in North America founded the Coursera platform. MIT and Harvard University jointly established edX platform and Udacity platform, and they are known as the three major MOOC platforms in North America. Through the operation of corporatization and marketization, more than 1,000 courses are offered, and the number of students has reached more than 12 million. The goal of MOOC is to realize that anyone can learn any knowledge at any place and at any time. Since MOOC explains popular professional knowledge through famous universities and teachers in the form of open network, it will soon be recognized by the market. In 2013, China's Peking University, Tsinghua University, Fudan University and Shanghai Jiao Tong University introduced MOOC. In 2015, China's Ministry of Education promulgated the "Opinions on Strengthening the Application and Management of Online Open Courses in Colleges and Universities", which further promoted the large-scale application of MOOC in China from small scale experiments. Due to the appeal of famous schools and teachers, MOOC uses the Internet to achieve teaching. Students can use fragmented time to learn, to a certain extent, to solve the problem of educational equity. However, there are also many shortcomings: MOOC is most active among top students in China's top universities such as 211 and 985 . The completion of the course is not high, and students' interest time is short. Many universities' MOOC is the copy of TV university. There is a lack of communication between teachers and students. The effect of learning can't be accurately checked. The terminal equipment of MOOC can only be PC. Reflecting on these situations, SMOOC (i.e., super MOOC) has been added. Compared with MOOC, it has increased any way. It hopes to learn in any way by means of cloud platform technology, big data technology and Internet + technology [2-5].

\section{BLENDED TEACHING PlATFORM}

Superstar FanYa platform is a multimedia learning platform launched by superstar company, which includes learning materials module, learning task module, interactive discussion and communication module, homework and examination module, achievement statistics module, etc. It can easily realize the four-in-one teaching mode, including the combination of theory and practice, pre-class and after-class, online and offline, traditional classroom and network classroom. The FanYa superstar platform can learn PPT courses on computers, mobile phones, IPAD, etc., watch animation courses and micro class videos, and read expanded information. The platform can't only increase classroom activity in classroom naming, but also discuss online in class, immediately release the accuracy rate in classroom test, and immediately release students' messages, which is conducive to the creation of classroom atmosphere. At the same time, teachers can be responsible for answering questions and group discussions online. The platform is conducive to attracting students' attention, giving full play to students' enthusiasm and initiative, and teachers also play the role of instructors.

\section{Blended TEACHING MethoD}

"Blended teaching" is a concept put forward by scholars Elliott Masie and Smith J in 2002. The connotation of blended teaching includes the mixture of behaviorism and constructivism, the combination of teacher led learning and student led classroom, and the combination of web based teaching and classroom teaching, which is commonly known as online and offline teaching. The blended teaching we are discussing now refers to the blending of online and offline teaching. Combined with the advantages of traditional classroom and network classroom, He Kekang, comes from Beijing Normal University, put forward the decisive role of teachers in teaching: guiding, inspiring and supervising students. At the same time, network tools and resources are used. With the help of advanced information tools such as multimedia, mobile phone, iPad and cloud platform, students' initiative, enthusiasm and creativity can be mobilized to improve their learning efficiency [3-5].

\section{The Application of Blended Teaching Method in HYDRAULIC PNEUMATIC TRANSMISSION AND CONTROL COURSE}

The design for blended teaching scheme is the core part of blended teaching method. Referring to Huang Ronghuai's "Design Framework of Blended Learning Course", we divide resources into four types: guidance material, Content material, assessment material and result material. The design block diagram of blended teaching is shown in Fig. 1.

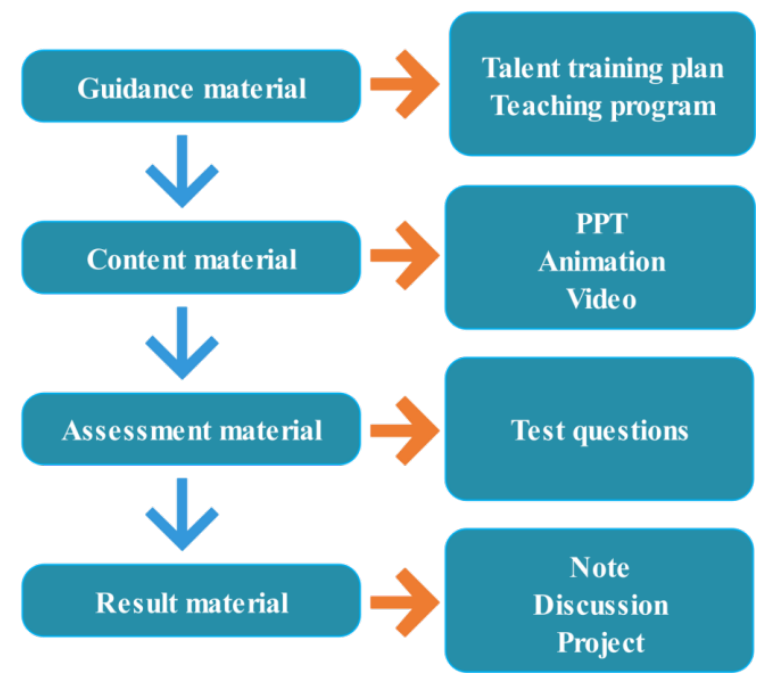

Fig.1. Block diagram and hierarchy of material resources for blended teaching

Guidance material refers to professional training programs and syllabus. Professional training program includes professional training objectives and specific implementation programs. The syllabus stipulates the hours, credits, selected courses, knowledge points, experimental time, projects, contents and assessment methods. They are programmatic documents. Content material refers to the specific concepts, formulas, theorems and applications of the subject in the form of teaching multimedia courseware PPT, teaching animation, word files and micro-class video. This is the basic part in hydraulic pneumatic transmission and control. Whether using 
traditional classroom or MOOC, it is the key part. The form can be changed, but the knowledge points can't be changed. Assessment material refers to test questions, items, discussion topics, etc. Result material refers to students' notes after completion of teaching, data after completion of tasks, calculation and analysis process, exchange of experience, summary, reflection, etc.

\section{A. Academic situation analysis}

At present, the orientation of our university belongs to the applied undergraduate. The difference between the applied undergraduate and the research undergraduate is that the research undergraduate mainly focuses on scientific research, especially basic science research, with emphasis on graduate training and scientific research. While the applied undergraduate focuses on the application of knowledge, so as to train the middle and senior talents who can work immediately after graduation for the society. On the other hand, the function of cultivating talents for research undergraduates is gradually losing at present. Counselors, head teachers and subject teachers do not have the time and energy to pay attention to students' growth and psychological conditions. Whereas, the applied undergraduates are gradually assuming the function of cultivating talents. At present, students in applied undergraduate are usually weak in basic knowledge, low in self-study ability, and low in initiative and poor in self-control ability. Only a small number of students have good foundation, high learning motivation and strong self-control ability. How to cultivate students with weak foundation and difficult to concentrate for a long time, and learn more professional knowledge, which is a problem faced by educators in the new era[4-6].

\section{B. Designing teaching goal}

"Hydraulic pneumatic transmission and control" course is the core basic course of mechanical and electronic engineering specialty, which is widely used in machine tool manufacturing, engineering machinery, aerospace and military industry. Through the course learning, the teaching goal of hydraulic pneumatic transmission and control course familiarizes students with the three basic laws of fluid mechanics. Students should master the common hydraulic components and the working principles of the three basic hydraulic circuits. They should have the ability to analyze and design the common hydraulic pneumatic transmission and control system, and lay a solid foundation for the follow-up course study, graduation design and in-depth study of new hydraulic technology. Students' independent self-study ability, team spirit and careful scientific research ability are further trained.

\section{Designing teaching contents of blended teaching}

Taking pressure control valve as an example, the teaching contents of four-in-one are shown in Table 1. We designed four videos that were captured by our own teaching team. First of all, it should learn the application video of pressure control valve; understand the classification in pressure control valves and typical applications in industrial field. Then, after watching the basic characteristics of the pressure control valve, the working principles of the relief valve and the pressure reducing valve are studied separately. These two contents offer video, and also offer FLASH based animation technology. The simulation teaching method is adopted. Finally, a concrete reduction circuit is explored in the classroom to check students' knowledge of the situation. The first four contents are online teaching implemented on FanYa platform. Students can pause video at any time in the process of learning, watch video repeatedly, or discuss online in the discussion area. In each part, testing topics are arranged to test the effect of learning. The last part is classroom communication and discussion realized in traditional classroom. The content is detailed in Table 1, which is a blended teaching mode based on FanYa platform.

TABLE I. BLENDED TEACHING MODE BASED ON FANYA PLATFORM

\begin{tabular}{|c|c|c|c|}
\hline Teaching content and project & \multicolumn{2}{|c|}{ Teaching form } & Teaching assessment \\
\hline Classification and application of pressure control valve & Online FanYa platform & Watch the video & Task point inspection and test subject \\
\hline Basic characteristics of pressure control valve & Online FanYa platform & Watch the video & Task point inspection and test subject \\
\hline Working principle of relief valve & Online FanYa platform & Cartoon and video & Task point inspection and test subject \\
\hline Working principle of pressure reducing valve & Online FanYa platform & Cartoon and video & Task point inspection and test subject \\
\hline Analysis on decompression circuit of actual hydraulic system & Offline class discussion & Discussion & Process assessment \\
\hline
\end{tabular}

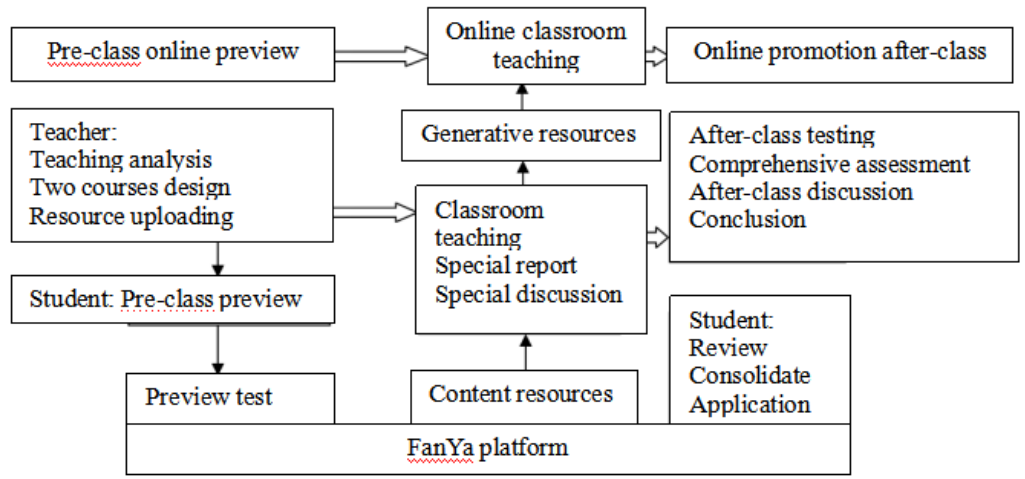

Fig.2. Implementation process of blended curriculum based on FanYa platform 


\section{Implementation process of blended teaching}

Before class, the teaching team formulates the syllabus according to the goal of personnel training, carries out the "two-course design" (i.e., curriculum design and classroom design), and reorganizes the syllabus. In the syllabus, the contents of teaching content, teaching difficulties, teaching methods and assessment methods are sorted out, and the syllabus is redesigned according to the requirements of the "8 items" design in our school, It needs to design the matching PPT of the course, shoot 10-20 minutes micro-lessons, design the pre-class online learning list, and set up task points and a small assignment. Assignments are less difficult and usually memorable knowledge points that can be answered by watching videos or reading textbooks. Then they upload the information in the FanYa platform. Students can visit the FanYa platform before class to complete preview pre-class, through mobile phones, IPAD, personal PC, notebook computers, etc. Students can download syllabus and PPT on the FanYa platform, read the course design sheet, watch the course videos, complete the related test preparation questions, and discuss in the discussion area. Teachers can check the proportion of watching videos and the correct rate of test questions to make personalized classroom content. Teachers can also answer students' questions in the discussion area and comment on students' communication. In the first stage, it can also directly import MOOC courses on other platforms in the FanYa platform, such as the introduction of the three major MOOC courses in China: Zheng Lifang, teacher of Chinese University MOOC Platform, is learning in the "Hydraulic Pressure Transmission and Control Course". In the traditional classroom, teachers can carry out course exchanges and special reports by using the mobile phone naming, answering and discussing methods. The course will be upgraded from scattered content material to result material, and the preliminary comprehensive application of knowledge will be completed.

\section{The Construction Of TEACHER TEAM In BLENDED TEACHING METHOD}

The development of blended teaching requires teachers to have rich teaching experience, double-teacher engineering application experience, and multimedia design and production ability. In the teaching exploration of hydraulic pneumatic transmission and control course, we have established a team of eight teachers, including one subject leader, three lecturers, two assistants and two experimental teachers. $100 \%$ of them are graduate students or above, and the title structure is one full professor and three associate professors. We have established a contingent of talents. The institute has invested a lot of money to complete the laboratory in hydraulic pneumatic transmission and control engineering. We implement team preparation, and brainstorm the syllabus, lesson plans and classroom designs together to prepare lessons. We designed a large number of course animation to facilitate students to learn.

\section{REFleCtion ON the Blended TEACHING Method}

The application of blended teaching mode in applied undergraduate is still in the initial exploratory stage, especially in the field of engineering, and there are still some problems to be reflected in the practice.
Blended teaching method can't emphasize MOOC and SMOOC separately. Simple application of MOOC and SMOOC in engineering has a ceiling. The new educational means and tools with the help of the Internet, such as distance education, network education, MOOC, SMOOC, etc., has flexibility and diversity. However, the degree of completion is not high, and there is almost no interaction between teachers and students. It is almost impossible to completely replace the traditional classroom, and the traditional classroom still has the value of existence. Teachers are still a very important role in teaching activities, which can't be replaced. Modern higher education needs to combine MOOC and other online classes with traditional classes.

The implementation of blended teaching requires an efficient team in educational engineers. Teachers' team building is also an important part in the blended teaching method. Without an efficient and high-level teacher team, there will be no first-class implementation of blended teaching. Teachers need to complete the transformation of educational engineers in the new era. Teachers in the new era must be able to complete knowledge learning ahead of time, and they are the pioneers of learning. At the same time, teachers must be able to use multimedia, Internet cloud platform, FanYa platform to complete the design and deployment of teaching. Teachers must be educational engineers.

The man-machine interface and usage habits of FanYa platform are not good enough. More users need to participate in the experience and improve its functions.

\section{CONCLUSION}

Based on the MOOC and FanYa platform, the blended teaching method overcame the limitations of traditional teaching, such as boring, rigid and inflexible. It fully preserves the unique guidance, inspiration and supervision of teachers in traditional classroom education. At the same time, it fully utilizes the flexibility of network teaching, attracts students, and makes full use of network, multimedia, fragmentation time, etc. Through the application of blended teaching method in the hydraulic pneumatic transmission and control course, this traditional course will be full of vitality. It is a beneficial attempt in the teaching reform of higher education, and has certain popularization value and reference value.

\section{REFERENCES}

[1] Li Dan, et al. The Reform and Innovation for Combination of MOOC and PBL in Analytical Chemistry Teaching [J]. Guangdong Chemical Industry, 2019, 46(16): 182-183. (In Chinese)

[2] Yin Jin, et al. Analysis on MOOC Education Ethics Based on the Experience of "Chinese University MOOC" and Its Significance to the Development of Education in Remote Areas [J]. Journal of Agricultural Library and Information Science, 2016(9): 119-123. ( In Chinese)

[3] Kuang Fangjun. Blended Teaching Reform of "Database Project" Course Based on WeChat Public Platform [J]. Industrial and Information Education, 2011. 8: 86-89. (In Chinese)

[4] Li Ying, Sun Rujun, Dong Weijian. Research and Discussion on Higher Vocational Teaching Reform Based on the Concept of "SPOC + Flipping Classroom" [J]. Journal of Harbin Vocational and Technical College, 2017 (6): 47-49. (In Chinese) 
[5] Deri L, Martinelli M, Bujlow T, et al. nDPI: Open-source High-speed Deep Packet Inspection [C] // Proc of Wireless Communications and Mobile Computing Conference, 2014: 617-622.

[6] Cheng Shaoyun, Yang Fang. Experimental Research on College English Blended Teaching Based on Mobile Terminal Cloud Class + SPOC [J]. Experiment Technology and Management. 2017(06): 183-188+214. (In Chinese) 